\title{
Spectrophotometric Determination of Hydrogen Peroxide by the Formation of Indamine Dye with the Catalyst of Water-Soluble Ironporphyrin
}

\author{
Taku Nakano and Ayako TakahaShI \\ Department of Pharmaceutical Sciences, Toyama Medical and Pharmaceutical University, \\ Sugitani, Toyama 930-01, Japan
}

\begin{abstract}
A water-soluble iron porphyrin, a meso-tetrakis(1-methyl-4-pyridyl)porphinatoiron(III) complex (FeTMPyPX; $\mathrm{X}=\mathrm{OCH}_{3}$ or halide), was successfully applied as a catalyst of indamine dye formation, which can be used for the determination of hydrogen peroxide in an acidic media. The dye formation process includes an oxidative coupling of $\mathrm{N}, \mathrm{N}$-dimethylaniline and 3-methyl-2-benzothiazolinone hydrazone with hydrogen peroxide. The absorbance of the formed dye was measured at $590 \mathrm{~nm}$ with a spectrophotometer. The materials were stable and the reaction was specific for hydrogen peroxide without any influence of molecular oxygen at low $\mathrm{pH}, 1-2$. The method showed easy handling in the concentration range of $(0.3-3.7) \times 10^{-5} \mathrm{~mol} \mathrm{dm}^{-3}$ with a correlation factor: $0.999_{8}$ and $\mathrm{RSD}=1.7_{4} \%$. This method can be used for the determination of hydrogen peroxide generated through enzymatic processes.
\end{abstract}

Keywords Hydrogen peroxide, hemin, porphyrin, indamine dye, water soluble porphyrin, spectrophotometric determination

Hemins are active sites in hemeprotein enzymes, such as horseradish peroxidase (HRP), which have been used in enzymatic assays of hydrogen peroxide produced by glucose oxidase ${ }^{1,2}$, oxalate oxidase $e^{3,4}$ or uricase. ${ }^{5}$ A convenient method for the determination of the activity of neutrophil leukocyte by measuring activated oxygen has been sought.6,7

Attempts to use artificial iron porphyrins have not always been successful to demonstrate their capabilities as catalysts of oxidation, since metalloporphyrins are easily decomposed under the required conditions. Successful cases were those in which electron-withdrawing substituents, such as halogens, were introduced into the peripheral moiety of porphyrin ${ }^{8-10}$ in order to protect them from activated species which were formed during the oxidation. In another case, metalloporphy- rins were deposited on an ion-exchange resin in order to inhibit the activated species from attacking each other. ${ }^{11}$

Another attempt was made to search for the conditions under which porphyrins survived; we have found the conditions under which a water-soluble ironporphyrin, meso-tetrakis(1-methyl-4-pyridyl)porphinatoiron(III) complex (FeTMPyPX $X_{5}$ ), catalyzed specifically the formation of an indamine dye by oxidative coupling of $\mathrm{N}, \mathrm{N}$-dimethylaniline and 3-methyl-2-benzothiazolinone hydrazone with hydrogen peroxide in an acidic media without any degradation of hemin (FeTMPyP complex) for the first time. The stability of the catalyst ensures the stoichiometry of the reaction. The reaction scheme (Fig. 1) was originally proposed for a system of ferric chloride in acid by Sawicki et al. ${ }^{12}$
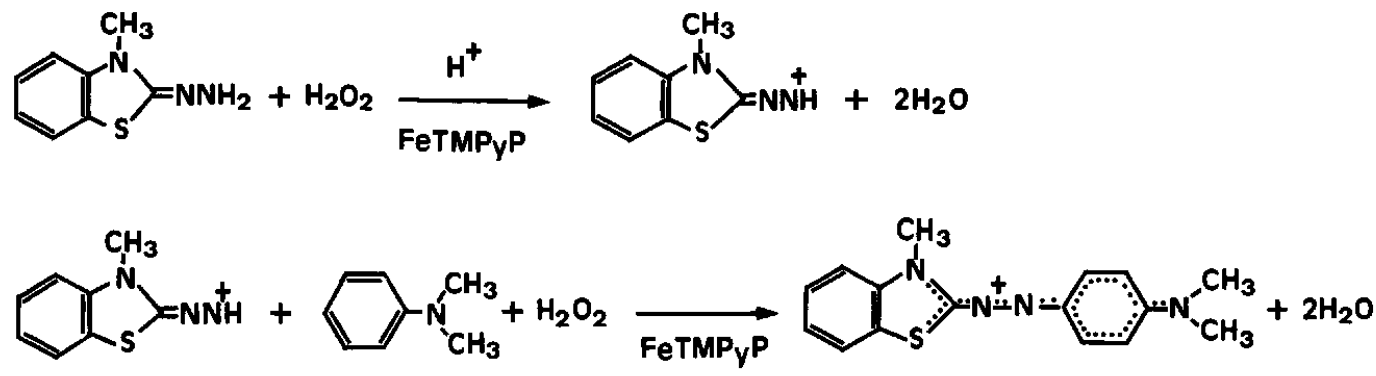

Indamine Dye

Fig. 1 Coupling reaction to form indamine dye. 


\section{Experimental}

\section{Materials and reagent solutions}

The reagents used should be water-soluble in an acidic media. Freshly distilled $N, N$-dimethylaniline (Wako Pure Chemical Ind.) was dissolved in $0.1 \mathrm{~mol}$ $\mathrm{dm}^{-3}$ hydrochloric acid to be $2.06 \times 10^{-2} \mathrm{~mol} \mathrm{dm}^{-3}$ (Solution A). 3-Methyl-2-benzothiazolinone hydrazone hydrochloride (Wako Pure Chemical Ind.) was dissolved in $0.1 \mathrm{~mol} \mathrm{dm}^{-3}$ hydrochloric acid to be $4.28 \times 10^{-3} \mathrm{~mol}$ $\mathrm{dm}^{-3}$ (Solution B). FeTMPyPX 5 was made by inserting iron $^{13}$ into meso-tetrakis(1-methyl-4-pyridyl)porphyrin ${ }^{14}$ (Dojindo Lab.); it was then and chromatographed and recrystallized from methanol-acetone. FeTMPyPX was dissolved in distilled water and the concentration adjusted spectrophotometrically to be $1.0 \times 10^{-4} \mathrm{~mol} \mathrm{dm}^{-3}$ (Solution P). A hydrogen peroxide solution $(\approx 30 \%)$ (Wako Pure Chemical Ind.) assayed iodometrically was diluted in distilled water before use (Solution $\mathbf{H}$ ). All other chemicals used were of reagent grade.

\section{Apparatus}

Hitachi-220A and Hitachi 100-10 Spectophotometers were used with attached water circulators. Tonometers with nitrogen inlets were used under anaerobic conditions. The pHs were checked with a Horiba H-7 LD pH meter.

\section{Results and Discussion}

\section{Formation of indamine dye and stability of the catalyst}

The spectral change of the reaction mixture is shown in Fig. 2. The spectra of solutions both with and without hydrogen peroxide demonstrated that hemin having a Soret band at $400 \mathrm{~nm}$ did not change at all during a reaction in an acidic media at $25^{\circ} \mathrm{C}$. The similar stability of the catalyst was confirmed when diluted (1/5). A purple color resulted with an absorption maximum at $590 \mathrm{~nm}$ of indamine dye; it was stable for hours. A homogeneous reaction catalyzed by a stable hemin and the resulting stable dye made the determination reliable.

\section{Calibration curve and reproducibility}

Portions of $5 \mathrm{ml}$ of the combined solutions of A $(14 \mathrm{ml}), \mathrm{B}(14 \mathrm{ml})$ and $\mathrm{P}(14 \mathrm{ml})$ were charged in spits, into which standardized solutions of hydrogen peroxide (final concentrations: $0-3.68 \times 10^{-5} \mathrm{~mol} \mathrm{dm}^{-3}$ ) were added using glass micropipets. After the solutions were well mixed with a Vortex mixer and kept standing for $1 \mathrm{~h}$ at $25^{\circ} \mathrm{C}$, the absorbances of the solutions in a $1.0 \mathrm{~cm}$ cuvette were measured at $590 \mathrm{~nm}$ vs. a blank solution. The final concentrations of the reagents were $6.88 \times 10^{-3} \mathrm{~mol} \mathrm{dm}^{-3}$ for $\mathrm{A}, 1.43 \times 10^{-3} \mathrm{~mol} \mathrm{dm}^{-3}$ for $\mathrm{B}$, and $3.3 \times 10^{-5} \mathrm{~mol} \mathrm{dm}^{-3}$ for $P$. The plot resulted in a straight line which passed through the origin. The apparent extinction coefficient of the dye at $590 \mathrm{~nm}$ was

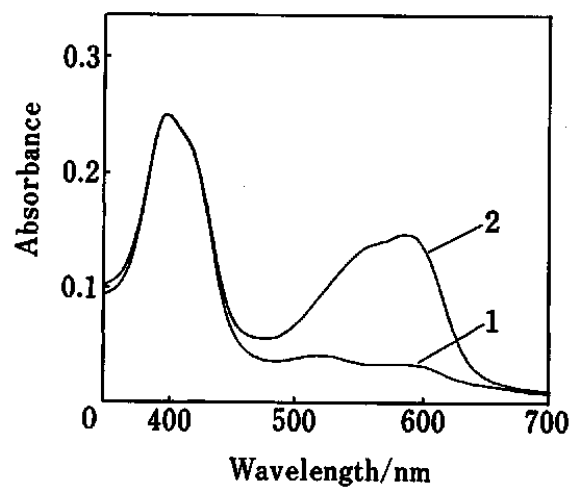

Fig. 2 Spectral change of the reaction mixture. The spectra were recorded $3 \mathrm{~h}$ after mixing solutions without (1) and with (2) hydrogen peroxide. The final concentrations of reagents were $3.44 \times 10^{-2} \mathrm{~mol} \mathrm{dm}^{-3}$ for $\mathrm{A}, 7.14 \times 10^{-3} \mathrm{~mol} \mathrm{dm}^{-3}$ for $B$, $3.3 \times 10^{-5} \mathrm{~mol} \mathrm{dm}^{-3}$ for $P$, and $3.68 \times 10^{-5} \mathrm{~mol} \mathrm{dm}^{-3}$ for $\mathrm{H}$. The $\mathrm{pH}$ was 1.0 and the temperature was $25^{\circ} \mathrm{C}$.

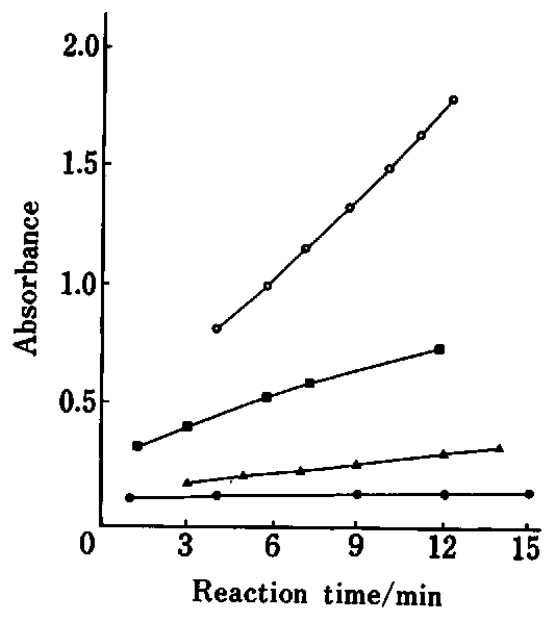

Fig. 3 Effect of $\mathrm{pH}$ on the reaction in air $\left(25^{\circ} \mathrm{C}\right)$. The final concentrations of reagents were $6.88 \times 10^{-3} \mathrm{~mol} \mathrm{dm}^{-3}$ for $\mathrm{A}$, $1.43 \times 10^{-3} \mathrm{~mol} \mathrm{dm}^{-3}$ for $B, 3.3 \times 10^{-5} \mathrm{~mol} \mathrm{dm}^{-3}$ for $\mathrm{P}$ and $1.84 \times 10^{-5} \mathrm{~mol} \mathrm{dm}^{-3}$ for $\mathrm{H}$. $\mathrm{pH}$ in phosphate buffers: (O) 1.0 ; ( $\triangle) 2.0 ;(\square) 4.0 ;(O) 6$.

$5.52 \times 10^{4}$, estimated from the calibration curve. The correlation factor for the calibration curve was $0.999_{8}$ and the relative standard deviation at the concentration of $1.84 \times 10^{-5} \mathrm{~mol} \mathrm{dm}^{-3}$ was $1.74 \%$ (five determinations).

\section{Effects of the $\mathrm{pH}$ and molecular oxygen}

The procedure adopted for the calibration was performed at various $\mathrm{pH}$ in phosphate buffers in air (Fig. 3). The absorbances at pHs at 4 and 6 increased much faster and almost linearly; they exceeded the expected values.

On the other hand, reactions performed under a nitrogen atmosphere (Fig. 4) indicated no rapid increases in the absorbances, as observed in air. At pH 4, though a faster increase was observed, it was revealed 


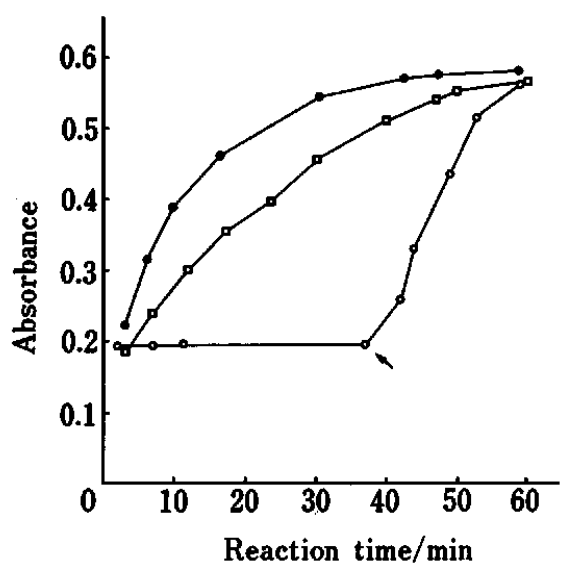

Fig. 4 Effect of the $\mathrm{pH}$ on the reaction in a nitrogen atmosphere $\left(25^{\circ} \mathrm{C}\right)$. The final concentrations of the reagents were the same as those given in Fig. 3. $\mathrm{pH}$ in phosphate buffers: ( $\square$ ) 2.0 ; (O) 4.0 ; (O) 6.0 . At the point indicated by an arrow (inset) the solution was exposed to air (see text).

that hemin was partially decomposed. At pH 6, no increase was observed after an immediate partial increase and the decomposition of hemin. When exposed to air, at an arrow (inset) the absorbance of the solution increased rapidly. The increases in the absorbances at higher $\mathbf{p H}$ in air should be caused by oxygen molecules which were activated by the catalyst or its fragment after degradation.

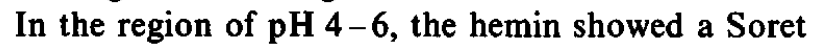
band at $423 \mathrm{~nm}$, suggesting an equilibrium which depends on the $\mathrm{pH}$. The spectral change at higher $\mathrm{pH}$ $(4-6)$ in air revealed only the decomposition; no intermediate species was observed. Further evidence is required to specify the mechanism of the reaction and the decomposition of hemin.

\section{Effect of temperature}

The reaction was followed in a similar manner as in calibrations at concentrations of $1.84 \times 10^{-5} \mathrm{~mol} \mathrm{dm}^{-3}$ of hydrogen peroxide at $25,35,45$ and $55^{\circ} \mathrm{C}$. The absorbances increased faster at 35 and $45^{\circ} \mathrm{C}$ and though the resulting spectra showed no degradation of hemin, it did indicate a slight formation of by-products at $45^{\circ} \mathrm{C}$. At $55^{\circ} \mathrm{C}$, the degradation of hemin was not negligible.

\section{Effect of foreign materials}

Inhibitions by substances which are supposed to be present or to be added were checked under the same conditions in a calibration at a concentration of $1.84 \times 10^{-4} \mathrm{~mol} \mathrm{dm}^{-3}$ (ten times excess to hydrogen peroxide), unless otherwise noted. The results are listed in Table 1. No interference was observed by the amino acids and carboxylic acids listed (glucose, albumin, urea and some of inorganic salts other than those noted below). In the presence of iron(II) ion the coupling was slightly accelerated and reached the expected value.
Table 1 Effect of foreign materials

\begin{tabular}{|c|c|c|c|}
\hline Compound & $\begin{array}{c}\text { Difference }^{\mathrm{a}} \text {, } \\
\%\end{array}$ & Compound & $\begin{array}{c}\text { Difference }{ }^{\mathrm{a}} \text {, } \\
\%\end{array}$ \\
\hline $\mathrm{NH}_{4} \mathrm{Cl}$ & +0.39 & Glycine & +3.2 \\
\hline $\mathrm{KCN}$ & +3.5 & L-Proline & +0.80 \\
\hline KI & +1.6 & DL-Phenyl- & +4.2 \\
\hline $\mathrm{NaN}_{3}$ & -6.7 & alanine & \\
\hline $\mathrm{NaBr}$ & -0.78 & Imidazole & -1.1 \\
\hline $\mathrm{Cu}\left(\mathrm{NO}_{3}\right)_{2}$ & -5.5 & Acetic acid & +0.39 \\
\hline $\mathrm{FeCl}_{3}$ & $-^{b}$ & Ascorbic acid & $-87^{c}$ \\
\hline$+\operatorname{EDTA}\left(10^{-2}\right)^{d}$ & $+2.9^{\text {e.f }}$ & Citric acid & 0.0 \\
\hline$+\operatorname{EDTA}\left(10^{-3}\right)^{\mathrm{d}}$ & $+1.2^{\mathrm{e}}$ & Urea & -1.7 \\
\hline$+\operatorname{EDTA}\left(10^{-4}\right)^{d}$ & $0.0^{\mathrm{e}}$ & Glucose & $-0.19^{\mathrm{g}}$ \\
\hline $\mathrm{FeSO}_{4}$ & +1.7 & & $-1.9^{h}$ \\
\hline $\mathrm{CaCl}_{2}$ & +2.1 & Glutathione & $-85^{c . i}$ \\
\hline $\mathrm{NiCl}_{2}$ & -1.9 & Albumin & +1.1 \\
\hline $\mathrm{MgCl}_{2}$ & -1.7 & Bilirubin & $-12^{j}$ \\
\hline $\mathrm{ZnCl}_{2}$ & -0.39 & Trichloro- & +1.0 \\
\hline $\mathrm{Co}\left(\mathrm{NO}_{3}\right)_{2}$ & -0.76 & acetic acid & $-5.8^{k}$ \\
\hline
\end{tabular}

a. Differences in $\%$ were those between numbers with and without foreign materials.

b. Iron(III) ions catalyzed the reaction with molecular oxygen in acidic media. ${ }^{12}$

c. Ascorbic acid and glutathione reduced hydrogen peroxide very quickly.

d. Concentration of EDTA.2Na in $\mathrm{mol} \mathrm{dm} \mathrm{d}^{-3}$.

e. $[\mathrm{Fe}(\mathrm{III})]=1.8 \times 10^{-5} \mathrm{~mol} \mathrm{dm}^{-3}$.

f. EDTA did not dissolve well. A supernatant was taken to be measured.

g. $1.8 \times 10^{-3} \mathrm{~mol} \mathrm{dm}^{-3}$.

h. $1.8 \times 10^{-2} \mathrm{~mol} \mathrm{dm}^{-3}$.

i. $50 \mathrm{mg} \mathrm{dl}^{-1}$.

j. $20 \mathrm{mg} \mathrm{dl}^{-1}$.

k. $1 \%$.

l. $3 \%$.

Though iron(III) ion catalyzed the coupling reaction in air, as indicated by Sawicki et al. ${ }^{12}$, it could be masked by adding EDTA to the solution (Table 1). Severe interference was observed in the case of reductive substances, such as ascorbic acid and glutathione.

The present method has shown some advantages regarding the determination of hydrogen peroxide, compared to the HRP methods..$^{1-5,15}$ The reagents are stable and easy to handle. The capability of coupling in a low $\mathrm{pH}$ - region $(\mathrm{pH}<2)$ ensures that the reaction is specific to hydrogen peroxide without any interference of dioxygen. Furthermore, the acidity of the solution prohibits the activities of enzymes which are present in the system. If applied clinically, this method is suitable for the determination of accumulated hydrogen peroxide in an organ, but not for that being formed successively. Easy handling of the reagents also provide an advantage regarding the automated determination. The determination of the activity of neutrophil leukocyte ${ }^{6,7}$ by measuring the amount of hydrogen peroxide produced is currently being investigated. 


\section{References}

1. N. Gochman and J. M. Schmitz, Clin. Chem., 18, 943 (1972).

2. T. T. Ngo and H. M. Lenhoff, Anal. Biochem., 105, 389 (1980).

3. M. F. Laker, A. F. Hofmann and B. J. D. Meeuse, Clin. Chem., 26, 827 (1980).

4. M. G. Li and M. M. Madappally, Clin. Chem., 35, 2330 (1989).

5. N. Gochman and J. M. Schmitz, Clin. Chem., 17, 1154 (1971).

6. K. Kakinuma, A. Boveris and B. Chance, FEBS Lett., 74, 295 (1977)

7. B. M. Babior, R. S. Kipnes and J. T. Curnutte, J. Clin. Invest., 52, 741 (1973).

8. P. S. Traylor, D. Dolphin and T. G. Traylor, J. Chem. Soc., Chem. Commun., 1984, 279.
9. T. Nakano, T. Wijesekera and D. Dolphin, Proceedings of 56th National Meeting of Chemical Society of Japan, Tokyo, April 1988, p. 1514.

10. S. Tsuchiya and M. Seno, Chem. Lett., 1989, 263.

11. Y. Saito, M. Mifune, S. Nakashima, H. Nakayama, J. Odo, Y. Tanaka, M. Chikuma and H. Tanaka, Chem. Pharm. Bull., 35, 869 (1987).

12. E. Sawicki, T. W. Stanley, T. R. Hauser, W. Elbert and J. L. Noe, Anal. Chem., 33, 722 (1961).

13. H. Kobayashi, T. Higuchi, Y. Kaizu, H. Osada and M. Aoki, Bull. Chem. Soc. Jpn., 48, 3137 (1975).

14. R. F. Pasternack, P. R. Huber, P. Boyed, G. Engasser, L. Francesconi, E. Gibbs, P. Fasella, G. C. Venturo and L. deC. Hinds, J. Am. Chem. Soc., 94, 4511 (1972).

15. R. K. Root, J. Metcalf, N. Oshino and B. Chance, J. Clin. Invest., 55, 945 (1975).

(Received June 19, 1990) (Accepted September 6, 1990) 